\title{
Consideraciones iconográficas sobre las decoraciones fijas anteriores al siglo XVIII del Palacio Real de El Pardo
}

\author{
Conservador de Pintura del Patrimonio Nacional
}

\author{
Juan Martinez Cuesta*
}

Parece ser que la idea de construir un auténtico palacio en el rico cazadero de El Pardo se la debemos al rey Felipe II, que tras su vuelta de Inglaterra, siendo aún Príncipe de Asturias, encomendó al arquitecto Luis de Vega la realización de las trazas del nuevo edificio que debía emular a los vistos en el país vecino. Las obras se iniciaron en 1544 y se prolongaron hasta 1557 en que se empezó a retejar el edificio a la manera flamenca -es decir, utilizando pizarra-constituyendo esta nueva técnica una de las características más típicas de la arquitectura madrileña del periodo barroco. Al tiempo que marchaban las obras se iba confeccionando un rico programa decorativo plasmado en importantes programas iconográficos para sus techos, y adquisición de pinturas de caballete para las paredes. Pero un trágico incendio ocurrido el 13 de marzo de 1604 dió al traste con este ambicioso proyecto. El 10 de agosto de 1605, el arquitecto Francisco de Mora elevó un memorial rey Felipe III manifestando que "no quedó en toda la casa suelo que pudiese servir ni pared que no haya menester descostrarse y blanquearse si no son las de las torres".

De este primer momento de la historia del palacio son numerosos los testimonios que poseemos sobre su decoración, pero el más importante es el de Argote de Molina, que en 1582 visitó este Real Sitio. En el capítulo XLVII de su "Discurso sobre el Libro de Montería" (publicado en Madrid en 1964 por Simón Díaz) encontramos una amplia descripción de la Casa y las alhajas que la adornan. Menciona la Galeria del Cierzo con los cuadros de Tiziano y Moro, la serie de vistas de ciudades españolas de Antoine van der Wyngaerde, la Capilla con el cuadro de Coxcie el "Descendimiento" copia de Roger van der Weyden y la importante Galería

* Conservador de Pintura del Patrimonio Nacional. 
de Retratos. Pocas son las noticias que da sobre la decoración de los techos. Menciona dos techos pintados por Pelegrin Resen de Amsterdam, "Vedriero de su Magestad, excellente Mathemático y Reloxero" y el único que ha llegado hasta nuestros días, «el aposento de la Camarera, que está pintado al fresco, de mano de Bezerra, natural de Baeca, cuyo Pinzel ygualó a los mejores pintores destos tiempos, y de mano de loan Baptista Bergamasco, y Rómulo Italianos, donde se vee la historia de Perseo, con muchas Tarjas a lo Romano, de admirable pintura sobre Estucon. Sorprende, que ha pesar de la minuciosa descripción que hace de la Galería de Retratos, no mencione el techo, obra de Antoine Populer o Pupiler.

La reconstrucción y nueva decoración del edificio se hizo con gran rapidez. Los trabajos decorativos se iniciaron en 1607 , bajo la dirección de Bartolomé Carducho y Pantoja de la Cruz a los que sucedió Pedro de Valencia, tras la muerte de ambos en 1608, en la elaboración de los programas iconográficos. La ejecución de los trabajos se convirtió en una de las empresas colectivas más importantes del reinado de Felipe III, tal como dice Carducho: "contó (...) con los mejores pintores del reyno". Sabemos los nombres de jos participantes (Patricio Caxés y su hijo Eugenio, Bartolomé Carducho y su nermano Vicente, Juan Pantoja de la Cruz, Francisco López, Juan de Soto, Fabricio Castello, Luis de Carvajal, Alejandro y César Semini, Jerónimo de Mora, Pedro de Guzmán, Jerónimo de Cabrera y Teododio Mingot) aunque sólo tres de estas decoraciones fijas han llegado hasta nosotros y el fragmento de una cuarta. Nos referimos a la "Historia de Esther" de Cabrera, "Historia de José», de Caxés, "Cacería con Aurora" atribuida últimamente a Carvajal, y «Toma de Granada» de Francisco López. Del resto de las obras nos han llegado multitud de testimonios literarios al igual que dibujos preparatorios que unido a lo conservado nos permite darnos una idea bastante completa de la gran belleza que alcanzó la decoración de este Palacio.

\section{GASPAR BECERRA. LA HISTORIA DE PERSEO h. 1562-1568. TORREÓN SUROESTE}

Constituye este conjunto el testigo más importante de lo que fue la decoración del Palacio en tiempos del rey Felipe II por ser el único que se salvó del terrible incendio. La obra fue realizada entre los años 1562 y 1568 y ocupaba no sólo el techo - lo conservado hasta nuestros díassino que el programa también se extendía por las paredes completando 


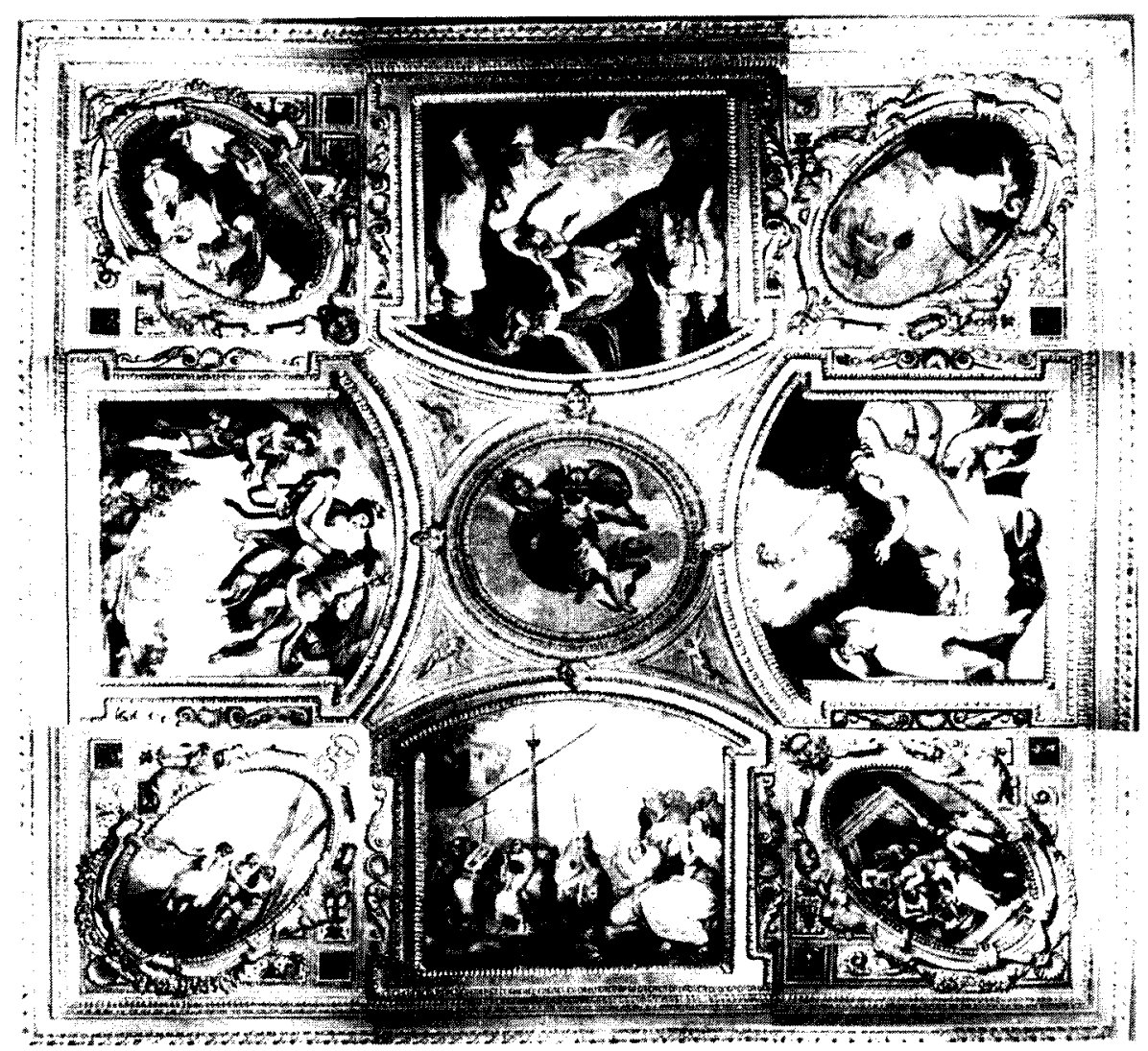

Fig. 1. Gaspar Becerra. La Historia de Perseo. Realizado entre 1562-1568. Torreón suroeste.

así toda la historia de héroe griego. Junto a Becerra se tiene referencia documental de otros artistas que también trabajaron, tales como Giovanni Battista Castello il Bergamasco, Romulo Cincinnato, Gaspar de Hoyos, Cosme de Susarte, Juan de Cervera y Miguel de Rivas. Ya que el trabajo no sólo se limitó a las escenas figurativas, pues támbién se desarrolló un rico repertorio de molduras y enmarcamientos, con mascarones y bichas, además de bellos paneles con decoración a candelieri.

La estructura del techo aparece centrada por un tondo con «La Apoteosis de Perseo". Se representa al héroe volando mostrándonos sus arrnas, una cimitarra y el escudo con la cabeza de la gorgona Medusa. Alrededor y alternando espacios rectángulares arqueados en la parte superior y ovalados se describe la historia en ocho episodios, utilizando como fuente literaria principal el libro de las Metamorfosis de Ovidio 
-tanto en su edición veneciana de 1517, como en la castellana de Jorge de Bustamante publicada en Amberes en 1545-, estos son:

1. «Dánae recibiendo la lluvia de oro»: la historia comienza en el momento de la concepción del héroe por la lluvia de gotas de oro que cayeron sobre Dánae, la hija de Acrisio, rey de Argos. El texto de Ovidio toca de pasada este episodio tan famoso de la Mitología y que ha servido de inspiración para tantos artistas. El mismo Felipe II poseyó una de las más bellas versiones de este tema realizada por Tiziano. El artista ha presentado todos los elementos típicos de esta representación. Desnuda, sobre un lecho, aparece Dánae en el momento en que su vieja criada permite la entrada de Júpiter, que transformado en lluvia de oro, fecunda a la doncella. Es innegable la huella de Tiziano.

2. "Nacimiento de Perseo»: Aunque Ovidio no hace mención ha este hecho, tras quedar encinta, Dánae dió a luz un hijo varón que recibió el nombre de Perseo. La composición sigue modelos iconográficos que nos resultan familiares, pues por la disposición de la figuras, más parece el nacimiento de la Virgen María o del propio San Juan Bautista. Esta coincidencia se podria justificar en la cristianización que se hace de muchos mitos cristianos en el Renacimiento por lo que Perseo, al igual que el Bautista, es un antecesor de Hércules, dios protector de la Península Ibérica.

3. «Embarque de Dánae y Perseo por mandato de Acrisio». Acrisio, padre Dánae habia sido advertido por el horáculo que un descendiente suyo le iba a matar, por eso cuando supo que su hija habia sido seducida por Zéus decide ordenar que tanto ella como su hijo, Perseo, fueran embarcados y abandonados a su suerte en el mar. Así vemos como Dánae y su hijo son montados en la nave ante las miradas sollozantes de un grupo de mujeres.

4. «Despedida de Perseo de su madre y Polidectes». Los náufragos fueron rescatados por un pescador que los llevó hasta la isla de Séfiros, donde entraron bajo la protección de su tirano, Polidectes. Allí se crió Perseo destacando por su gran valor y belleza sobre los demás jóvenes. Pronto tuvo ocasión de demostrarlo porque durante la celebración de un banquete en honor a Polidectes se comprometió a presentarle como regalo la cabeza de Medusa. Por lo que nuestro héroe tuvo que separarse de su madre y salir a buscar tan preciado trofeo. Vemos a Polidectes de espaldas, acompañado por Dánae, y a Perseo en actitud de avanzar.

5. "La Entrega de Atenea y Mercurio de sus dones a Perseo». Pero Zeus no abandona a su hijo, por lo que envía a Atenea y Mercurio en su ayuda. Vemos a nuestro héroe recibiendo de manos de los dioses un es- 
cudo y una espada cimitarra que a partir de ahora serán sus armas. Aquí está la famosa figura del dios Mercurio cuyo dibujo presentó Beverra al rey Felipe II y del cual éste exclamó: “¿No habéis hecho más que ésto?». Este dibujo se conserva actualmente en el Museo del Louvre de Paris.

6. «Perseo y las Grayas»: Según el texto de Ovidio, una vez liberada Andrómeda y tras el banquete de bodas -ya sumidos en los efectos del vino-, uno de los invitados preguntó a Perseo como había conseguido la cabeza de Medusa, cosa que éste no tuvo ningún reparo a relatar. $Y$ así contó como antes de alcanzar la casa de las Gorgonas, nuestro héroe tuvo que burlar a las Grayas, Enio Pefredo y Dino, las hijas de Forcis y Ceto, cuya misión era impedir el paso hasta su morada. La escena nos muestra a dos de las Grayas en el momento en que una de ellas, tras acabar su turno de vigilancia, se dispone a entregar el único ojo que poseían a otra de sus hermanas y así continuar con su tarea. Por encima vemos a Perseo que desciende volando para aprovechar este momento, en que no podian ver, para robarles el ojo.

7. «Perseo se dispone a cortar la cabeza a Medusa»: Ante los atónito oídos de los comensales, el hijo de Dánae siguió su relato explicando como había llegado a la casa de las Gorgonas, también hijas de Forcis y Ceto, que vivían cerca del país de las Hespérides, siguiendo el rastro dejado por todos los hombres y animales que habían sido petrificados por Medusa, pues sus ojos convertian en piedra todo lo que miraban. Aprovechando el momento en que dormía, porque tenía los ojos cerrados, nuestro héroe decide decapitarla tal y como vemos en la composición. Perseo se dispone a sestar el golpe con su espada curva sobre la figura de Medusa que descansa en un lecho entre las figuras petrificadas de sus esclavos.

8. "Nacimiento de Pegaso": termina este ciclo con el nacimiento del famoso caballo alado Pegaso, que fue el fruto de la tierra fecundada por la sangre de Medusa. Nada más nacer, el animal voló hácia el Olimpo para ponerse al servicio de Júpiter. En la parte superior aparece nuestro héroe que vuela de espaldas, ajeno al prodigio. En primer plano vemos a Pegaso con las alas abiertas iniciando su vuelo.

Seguia el relato por las paños de las paredes con los episodios de la liberación de Andrómeda, con lo que el programa iconográfico quedaba completo al igual que su significado político. Parece ser que un uso inicial de esta pieza mucho más privado hizo que se concibiera este programa por lo que usos posteriores, como pieza de la Camarera, hacen que resulte algo incongruente su simbología con su uso. Se ha interpretado como una alegoría de la victoria española sobre sus enemigos. 

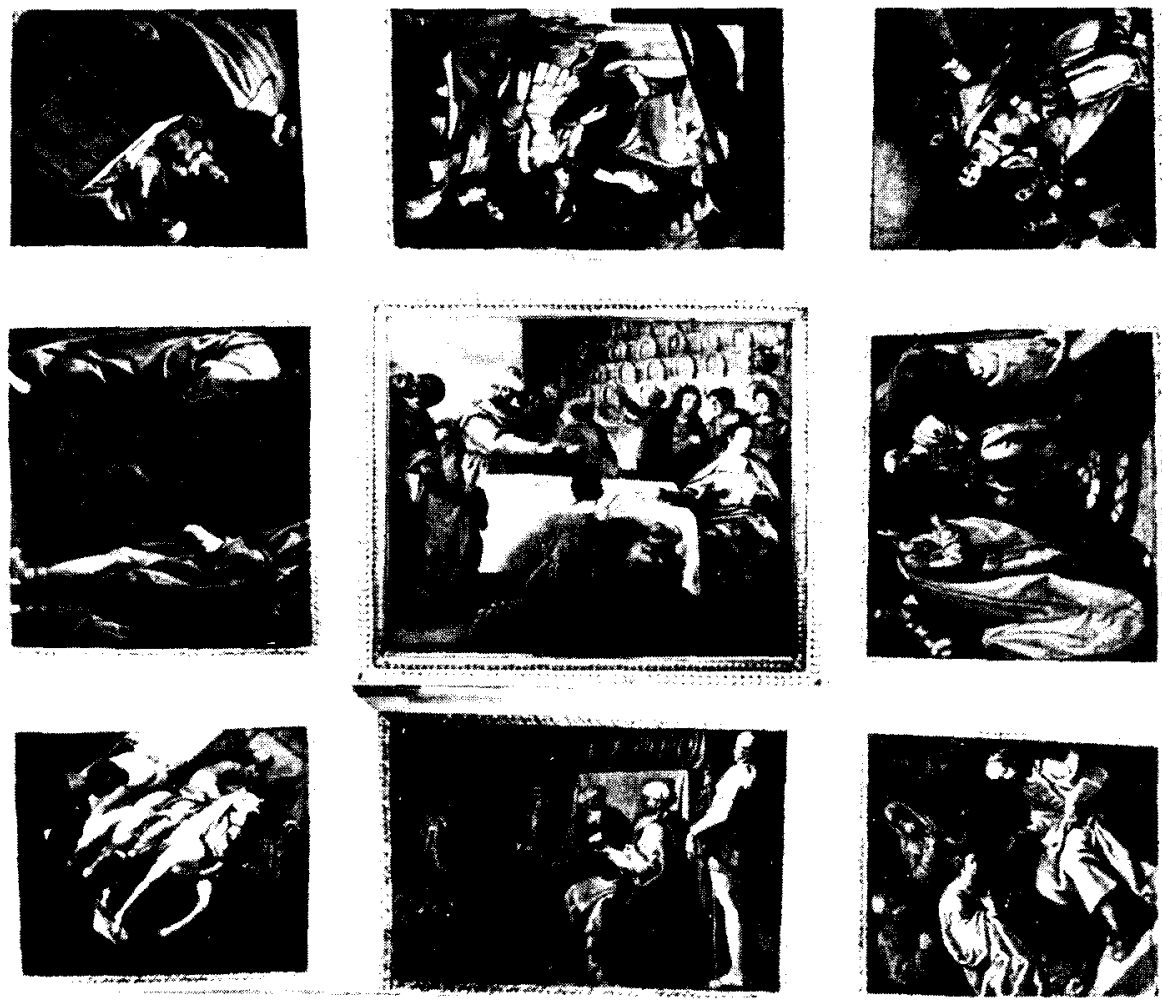

Fig. 2. Jerónimo de Cabrera. Historia de Esther. Sala de las Mujeres Fuertes.

Pasamos ahora a considerar los techos que realizados durante el reinado de Felipe III.

11. JERÓNIMO DE CABRERA. HISTORIA DE ESTER $h .1613 \cdot 1617$. QUIZÁ AYUDADO POR TEODOSIO MINGET

Poco es lo que se sabe de este artista y si no fuera por esta obra muy escaso seria lo que de él habria llegado hasta nosotros. En 1613 se le encargaron la realización de las bóvedas del Cuarto del Rey y del Cuarto de la Reina. Las primeras trazas que mostró de este trabajo no gustaron por considerar que no eran lo suficiente suntuosas y ricas para el fin tan alto de estas piezas. La revisión del proyecto supuso una elevación de su precio. En 1617 ya se habian terminado según consta en una relación presentada al Rey, en ella no sólo se incluia lo aquí realizado, sino también sus trabajos en el Convento de Capuchinos de este mismo Real Sitio. 
Si para el Cuarto del Rey se presentó la "Historia de Asuero" por considerarla la apropiada por su significado, en el Cuarto de la Reina el personaje escogido fue su esposa, la heroína bíblica Esther. Nada nos ha llegado de la primera decoración, constituyendo este segundo conjunto el mejor ejemplo del buen hacer de este artista, cuyo estilo todavia es heredero de los formas y volúmenes tan magestuosos de la anterior centuria.

El techo se divide en dos parte: la superficie de éste con la historia de Esther dividida en nueve episodios y la escocia, dividida en doce espacios triangulares donde aparecen los signos del zodiaco en correspondencia con los doce meses del año, alternando con matronas féminas que simbolizan virtudes. Por último, en las esquinas, las cuatro estaciones.

\section{Estos son los episodios escogidos del Libro de Esther:}

1. Mardoqueo descubre una conspiración contra el Rey Asuero (1, m-r). En los preliminares de este libro aparece este episodio que marca el inicio de la envidia de Amán contra el judio Mardoqueo por los honores que recibió del Rey Asuero por denunciar la conspiración que preparaban los eunucos del Palacio para acabar con su vida. Sentado a una mesa vemos al anciano Mardoqueo hablando con el Rey, de perfil al espectador, que le escucha. Junto a ellos otros personajes de la corte, soldados, y criados.

2. Repudio de Vasthi y elevación de Esther (I, 9-20). Vivía con Mardoqueo su sobrina Esther, mujer de gran belleza y juicio, en la que el Rey se fijó y decidió esposarla y convertirla en su favorita repudiando, así, a la reina Vasthi. Vemos a la nueva reina inclinada ante Asuero, al tiempo que un sacerdote le presenta la corona que va a ceñir.

3. Esther se presenta ante el Rey por instancia de Mardoqueo (II, 22) De nuevo la vida del Rey corre peligro, pues otro grupo de eunucos planean acabar con él. La noticia llega a oídos de Mardoqueo y éste pide a su sobrina que informe a Asuero del peligro inminente que corre. Vemos a la Reina, de pié ante su esposo, explicándole, ante miradas y gestos de sorpresa, el peligro que sobre él se acecha.

4. Ayuno y plegaria de Esther (IV, 16). Este inecho desata las envidias de Amán, favorito del Rey, que viendo como la reina y su tío se interponen en sus ambiciones políticas decide eliminarlos y junto ellos a todo el pueblo judio. Ante la amenaza, Mardoqueo pide de nuevo a Estner que se presente ante su esposo y denuncie el hecho. Aparecer ante el Rey y dirigirle la palabra sin ser llamado era un delito castigado con la muerte, por eso Esther pide a su pueblo que guarde tres días de ayuno y penitencia para invocar la ayuda de Dios. Asi vemos a la misma Reina, acompañada por sus damas, arrodillada e invocando la protección divina. 
5. Esther invita al Rey a un banquete $(V, 1)$. Tras el ayuno, Esther se levantó, se vistió con sus mejores ropas y se presentó ante Asuero para invitarle a un banquete que iba a dar en sus habitaciones. Vemos a la reina desvanecida ante la presencia de Asuero que con gestos comprensivos le invita a que confíe en él.

6. El Rey acude al banquete de Esther acompañado por Amán (V, 5). $Y$ así fue, el Rey se presentó junto con su favorito para compartir la mesa de la Reina. Tras acabar la comida Esther pide al Rey y Amán que acudan al día siguiente para volver a comer juntos.

7. El Rey no puede conciliar el sueño (VI, 1). Vuelto a sus habitaciones y recostado en su lecho, Asuero no puede conciliar el sueño, por lo que pide a sus criados que le lean los anales de su reino, percatándose como Mardoqueo le ha salvado la vida y no ha recibido ninguna recom. pensa que premie estos esfuerzos.

8. Humillación de Amán y honores tributados a Mardoqueo (VI, 11). Preguntado a Amán cual debía ser la recompensa de aquél que salva la vida de su Señor, éste contesta que debía ser ricamente vestido y alhajado, y paseado montado en un caballo real por toda la ciudad, con un heraldo que vaya pregonando sus glorias. $Y$ así ordena Asuero que se haga con Mardoqueo, ante la estupefacción y envidia de Amán. En la escena vemos al propio Amán tirando de las riendas del caballo blanco que monta Mardoqueo.

9. Segundo banquete de Esther y caida de Amán (VII, 7). Por segunda vez acuden el Rey y su favorito ante la reina, que aprovecha ese momento para desvelar al Rey la amplitud y gravedad de los planes de Amán que pretende exterminar al pueblo judio, en el que se incluye la propia reina. Asuero se levanta indignado y Amán se hecha a los pies de Esther pidiendo clemencia, tal y como refleja esta escena, ante la mirada y gestos de sorpresa del resto de los comensales. La historia termina con el castigo de Amán, victima de los mismos suplicios que había preparado para Mardoqueo.

El espacio que media entre el techo y la pared aparece compartimentado por doce lunetos en los que se cobijan los doce signos del zodiaco entre ios que aparecen representadas ocho matronas, y las cuatro estaciones en las esquinas. Siguiendo este mismo orden pasamos a considerar estas representaciones femeninas cuya identificación resulta bastante confusa por la ausencia de símbolos que las definan plenamente. La clara identificación de algunas ha llevado a pensar que representan a las mujeres fuertes de la Biblia, aunque otros estudiosos han planteado que sean las virtudes que deben acompañar a una Reina. Asi la primera represen- 
tación podría ser Maria Magdalena desprendiendose de sus joyas como símbolo de arrepentimiento de sus pecados y despego a las riquezas temporales; sigue una elegante mujer sentada junto al tronco de una palmera, alusión al matrimonio y a la fecundidad personificada en Tamar, nuera de Judá. En el siguiente tramo encontramos una mujer que alza la mirada y las manos mostrándonos los brazos, como símbolo de la caridad o también de acción de gracias como hizo María, la hermana de Moisés, tras cruzar el mar Rojo; la siguiente matrona es una anciana, quizás Sara -esposa de Abraham - o Isabel, amamantando un niño que podría ser Isaac o el propio San Juan Bautista. Siguen otras dos figuras, primero una esforzada joven que con un mazo y un clavo golpea un pilar, quizás una figuración de la Virgen María tallando la piedra angular que es Jesucristo, que podría ser una alegoria a la fuerza; la siguiente figura es otra joven que sostiene un cayado con su mano derecha, símbolo de consuelo, alivio, de pastoreo, siendo Raquel, hija de Labán, la personalidad que más se ajusta a esta representación. Termina la serie con Judit que nos muestra la cabeza de Holofernes, como referencia a la astucia; $y$, por último, otra joven sentada con las manos apoyadas en sacos llenos de grano, quizás trigo, símbolo de la generosidad no sólo de la tierra sino también del gé. nero humano, tal como hizo Rut con su suegra Noemi.

Alternando estas figuras aparecen los doce signos del Zodiaco con su representación alegórica. Siguiendo el mismo orden empezamos con Aries, que corresponde al mes de marzo, con unos campesinos podando una viñä; Tauro - abril- con un paisaje con unas figuras, quizás pastores, y animales en segundo plano; Géminis que corresponde al mes de mayo presenta dos cazadores; Cáncer simbolizado por un grupo de campesinos segando, actividad que continúa con Leo, donde los campesinos golpean el heno; Virgo también es un signo relacionado con la diosa Ceres, pero aquí se simboliza con unos pescadores lanzando su red en un rio; Libra es el final del verano y viene marcado con la vendimia; Escorpio marca el inicio del otoño y aunque su representación es un cazador, aqui se ha preferido presentar dos caminantes a la puerta de una venta; Sagitario es la preparación para el invierno, por eso vemos un grupo de leñadores en su faena de reunir leña; Capricornio, diciembre, se une a la matanza del cerdo; Acuario viene marcado por los últimos rigores del invierno, por eso vemos un campesino con leña, y, por último, Piscis que simboliza el despertar de la naturaleza y la vuelta a las faenas agricolas.

Por último, en las esquinas encontramos cuatro figuras que se han relacionado con las estaciones del año. La Primavera seria una joven de la que caen flores; el Verano un joven rubio con un ramo de flores y una antorcha; el otoño, una persona madura con una vara; y el Invierno una mis- 
teriosa figura femenina envuelta en un manto de estrellas que sostiene la luna con su mano izquierda.

III. JERÓNIMO CAXÉS Y COLABORADORES. HISTORIA DE JOSÉ h. 1607-1612. GALERIA DE LA REINA

Esta Galeria es uno de los conjuntos más importantes conservados de los aquí presentados. Su situación privilegiada dentro del Cuarto de la Reina, en el lado septentrional, hizo que recibiera una muy cuidada decoración. Su estructura corresponde al tipo de pieza llamada "Galería larga» o de paseo, tan habitual en los palacios manieristas cuyo uso era bastante variado ya que podían servir como lugares públicos de reunión, audiencias, o para diversiones, comedias y conciertos, pero no bailes pues se decía que eran muy angostas para este uso.

El amplio techo fue dividido en nueve tramos, tres laterales y uno central, en los que alternando escenas rectangulares con ovales se describe la vida de José en doce episodios, más el central que representa la Apoteosis de este hijo de Israel. La obra fue realizada entre los años 16071612 por Patricio Caxés y un amplio equipo de colaboradores, entre los que destaca su propio hijo, Eugenio. El relato está tomada del Libro del Génesis (IV Parte, Cap. XXXVII al L).

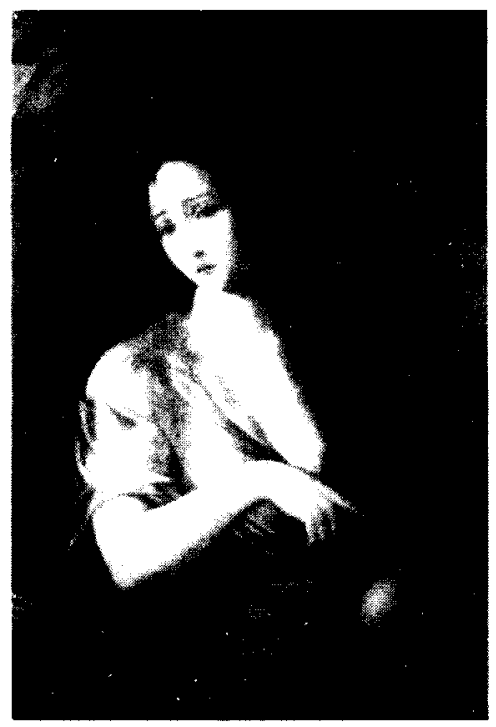

Fig. 3. Jerónimo Caxés y colaboradores. Historia de José. 1607-1612. Galeria de la Reina. 
1. José explica sus sueños a sus hermanos (XXXVII, 5-11) Aparece José en el centro de la composición, entre sus hermanos, en el momento que les cuenta sus sueños. Estos fueron dos, primero soñó que estaba atando gavillas en el campo, junto a sus hermanos, cuando observó como la suya se mantenía derecha mientras que las de ellos la rodeaban y se inclinaban hácia la suya, tal como se vé en segundo plano. El segundo relato lo vemos reflejado en el celaje de la obra, cuando José vió como el sol, la luna y once estrellas se inclinaban ante él. Estas declaraciones aumentaron la envidia que le tenían sus hermanos, como se puede apreciar en las aptitudes que presentan, según José les va desvelando sus sueños.

2. José es arrojado a un pozo por sus hermanos (XXXVII, 24). Su envidia pudo más que el amor hácia su hermano, por eso decidieron matarlo y encubrir el asesinato diciendo que había sido devorado por algún animal feroz. Pero Rubén, el mayor de los hermanos, convence al resto para que en lugar de acabar con su vida, le arrojen a un pozo, donde piensa luego liberarlo. Con formato oval, vemos el momento en que José, despojado de su túnica y atado con sogas en arrojado a un pozo por dos de sus hermanos, mientras unos le contemplan y otros, en segundo plano, planean como engañar a su padre Jacob para ocultar su crimen.

3. José es vendido a los mercaderes ( $x$ XXVII, 25-28). Pero en esto vieron aparecer una caravana de ismaelitas que iba hácia Egipto que les hace cambiar de idea. Es el propio Judá quien sugiere vender a José a estos mercaderes, en un ápice de amor fraternal, y evitar que su muerte recaiga sobre sus conciencias. El resto de los hermanos, entre los que faltaban Rubén, aceptan el cambio de planes y liberan a José de su prisión para venderlo. Tal y como vemos, José en el centro, entre uno de sus hermanos que toma las veinte piezas de plata que le ofrece uno de los madianitas. A un lado, un grupo de dromedarios un tanto desproporcionados respecto a sus jinetes.

4. Jacob contempla la túnica ensangrentada de José ( $x x x, 33)$. Con miradas y aptitudes cómplices, los hermanos de José, encabezados por Judá, muestran al anciano Jacob su túnica ensangrentada. Este levanta las manos al observar que no hay duda, que su hijo favorito ha sido devorado por un animal feroz.

La escena transcurre en un elegante interior clásico, centrado por un arco de medio punto enmarcado por dos columnas de fuste liso, como si se tratara de un escenario de teatro. La Biblioteca Nacional de Madrid guarda un dibujo de esta composición. 
5. José huye de la mujer de Putifar (xxxıx, 11-15). Sigue el Libro del Génesis con la historia de Judá y Tamar, para volver a José en el capitulo siguiente, el treinta y nueve. Como es sabido, José fue vendido en Egipto como esclavo al capitán Putifar, que aprovechando las brillantes dotes del joven lo puso en la cabeza del gobierno de su hogar. Al mismo tiempo, José empezó a sufrir el acoso de su esposa que le requería en su lecho. En una de estas ocasiones, la mujer de Putifar le agarró por la ropa y al querer huir, nuestro héroe la perdió. Si examinamos con detenimiento este episodio, es fácil concluir que en un principio esto era lo que aquí se representaba, pero el paso del tiempo - cuando esta galería fue tabicada - ha hecho que nos haya llegado fragmentado. La figura de José, con el rostro lleno de temor mirando hácia atrás, es original del techo, mientras que el amplio pilar viene a rellenar el espacio donde aparecería el motivo de su huida, el lecho donde descansaria la mujer del capitán egipcio.

6. José explica los sueños del Faraón (XLI, 17-32). Con la evidencia del manto, Putifar encarceló a José, lugar donde permaneció dos años. Allí conoció al escanciador y al panadero del faraón a los que también les interpretó sus sueños. $Y$ fue por estas artes, por lo que José fue reclamado ante el Faraón, ya que este tuvo dos sueños cuyo significado no pudo ser hayado por todos los sabios y magos del pais. Aparece José, afeitado y con ropas limpias, ante el Faraón que sentado en un elegante sillón, bajo dosel y protegido por su guardia, le escucha. Tras el joven vemos un grupo de ancianos que también escuchan, unos con la cabeza inclinada y otros con gesto de disgusto, sus explicaciones. La escena transcurre en una amplia estancia, abierta a una paisaje por un amplio arco de medio punto ricamente adornado con columnas y figuras. En el paisaje se ve una ciudad, junto a la cual transcurre un rio, donde pacen dos grupos de siete vacas, el uno hermosas y lustrosas y el otro de mal aspecto y malicientas. Tras ellos dos cañas con siete espigas cada una, que al igual que los animales, unas son lozanas y buenas y las otras flacas y asolanadas. Con estas señales, Dios quería mostrar al Faraón su voluntad de someter al mundo a siete años de abundancia seguido por otros siete años de carestía y hambre. Se conserva un dibujo preparatorio de esta obra en los Uffizi.

7. José hace acopio de viveres (XLI, 47). Al descifrar sus sueños, el Faraón decide convertir a José en su mano derecha entregándole su anillo para que con su inteligencia gobierne su casa y todo el país. $Y$ así, según la voluntad de Dios, vinieron siete años de ricas cosechas que José aprovechó para llenar todos los graneros y despensas del Faraón, 
tal y como vemos en esta escena. En primer plano aparece José ricamente ataviado señalando a un grupo de trabajadores que están llenando un saco de grano. Al fondo una fila de personajes con sacos a sus espaldas entran en el granero real. La escena transcurre en un interior clásico, donde vemos un amplio arco de medio punto tras el cual se divisa una ciudad. Destaca por su gran belleza la elegante postura del personaje que muestra a José el trabajo de sus compañeros. Se conserva un dibujo cuadriculado de esta obra en el Museo Metropolitano de Nueva York.

8. José mete a sus hermanos en la cárcel (xLII, 17). Cuando comenzaron los siete años de carestía, el hambre empezó a azotar el mundo, salvo en Egipto, por lo que Jacob decidió enviar a sus hijos al país del Nilo para hacer acopio de grano y asi no morir de hambre. Enseguida José reconoció a sus hermanos a los que quiso poner a prueba, acusándoles de ser espias que venían a ver los puntos débiles del país, por lo que decidió encerrarlos tres dias en la cárcel. Aparece José, a nuestra izquierda, junto a los sacos llenos de grano de sus hermanos, cuando los soldados les conducen a la cárcel, en el momento que uno de ellos se humilla ante él pidiéndole clemencia.

9. La copa de José en el saco de Benjamín (XLIV, 12-17). José permitió que sus hermanos regresaran junto a su padre, pero con la promesa de volver con Benjamín, el más pequeño, dejando como rehén a Simeón. En su segundo viaje a Egipto nuestro héroe, tras agasajar a su gente, decide esconder su copa en el saco de su hermano pequeño. El episodio muestra el momento que uno de sus criados encuentra el preciado vaso en el saco de grano, al tiempo que escucha las quejas de Benjamín. A nuestra derecha vemos a otros servidores buscando en los sacos ante los ojos atónitos de los hijos de Israel. El episodio transcurre en un exterior rodeado de construcciones clásicas.

10. José se presenta a sus hermanos $(X L V, 3)$. No pudiendo más esconder su emoción, José se dá a conocer a sus hermanos y éstos, asuntados caen arrodillados ante él. Entonces, emocionado y con el rostro lleno de lágrimas, se abraza al cuello de Benjamín, tal y como muestra la obra. La escena transcurre en un exterior urbano de corte clásico. Existe un dibujo preparatorio en el Museo de los Uffizi.

11. Encuentro de Jacob y José en Gosen (XLVI, 29). Siguiendo la voluntad de Dios, José manda llamar a su padre y al resto de su gente a Egipto para sobrevivir de la carestía que asola al mundo. No pudiendo esperar, José se adelanta y sale al encuentro de Jacob a Gosen. A un lado de la composición aparece Jacob, anciano de larga barba blanca, que 
abraza a su su perdido hijo, al tiempo que exclama: «Ahora ya puedo morir, porque he visto tu rostro y estás todavía vivo". Junto a ellos algunos de los hijos de Israel, que con capas y cayados presencian emocionados el encuentro. Tras ellos los rebaños y el resto de la gente. Se guarda un dibujo también cuadriculado de esta obra en la Real Academia de Bellas Artes de San Fernando.

12. José presenta a su padre ante el Faraón (XLVII, 7). Termina el relato pictórico con el momento en que José presenta a su padre y sus hermanos al Faraón y éste les ofrece las mejores tierras del país para asentarse.

13. Apoteosis de José. Como escena final, en el centro del techo, encontramos esta entrada triunfal de José sentado en un carro tirado por dos caballos blancos ante una multitud que le aclama. La escena transcurre en una calle. De esta obra se conserva un dibujo en el Museo de los Uffizi (Florencia).

Flanqueando esta escena central encontramos ocho recuadros donde aparecen representados cuatro personajes del Antiguo Testamente alternando con cuatro Sibilas. A un lado tenemos a la Sibila de Samos, llamada Fito, una de las menos conocidas, siguen los profetas Moisés, con sus rayos en la cabeza, y Jonás, sentado sobre un monstruoso pez, para terminar con la sibila Délfica que nos muestra el libro del que leía sus famosos oráculos. En el lado opuesto vemos al sibila Libica escribiendo un oráculo, el profeta Daniel con un libro que muestra a un discípulo, el rey David, con corona y cetro, y la sibila de Cumas, que aquí es una elegante joven que descansa de la lectura. Enmarcando las escenas de la historia de José, encontramos unas bandas decorativas donde encontramos pequeñas escenas de puttis jugando con animales o encaramados a guirnaldas, grupos de figuras bailando y paneles de decoración a candelieri. En los ejes y marcando el ritmo de la alternancia de las escenas bíblicas aparecen seis pequeños tondos donde se han representado otros tantos profetas. Estos son Jeremías, Amós y Samuel a un lado, y Joel, Elías e Isaias, en el opuesto, todos ellos leyendo o meditando sobre los libros donde han escrito sus profecías.

El efecto final del techo es de gran riqueza consiguiendo revivir de forma piena su primitivo aspecto aunque el paso del tiempo y sucesivas tabicaciones de este espacio, como posteriores decoraciones, la hayan dañado en exceso. Actualmente el Patrimonio Nacional ha querido resaltar la importancia de esta Galería situando en ella dos importantes cuadros de sus colecciones pictóricas. Estos son el «Retrato ecuestre del Infante don Juan José de Austria", obra de Ribera y la llamada "Cuerna», de Diego Velázquez. 
IV. ATRIBUIDO A LUIS DE CARVAJAL, ANTES A VICENTE CARDUCHO. CACERIA CON LA AURORA. CÁMARA DE LA REINA DE HUNGRIA

Una nueva lectura de las tasaciones de las pinturas de El Pardo ha permitido documentar esta obra como de Luis de Carvajal ( $¿$ ?) siendo el único ejemplo que nos ha llegado de este artista de las decoraciones que realizó para este Palacio. Se trata de uno de los techos más hermosos y de mayor riqueza ornamental.

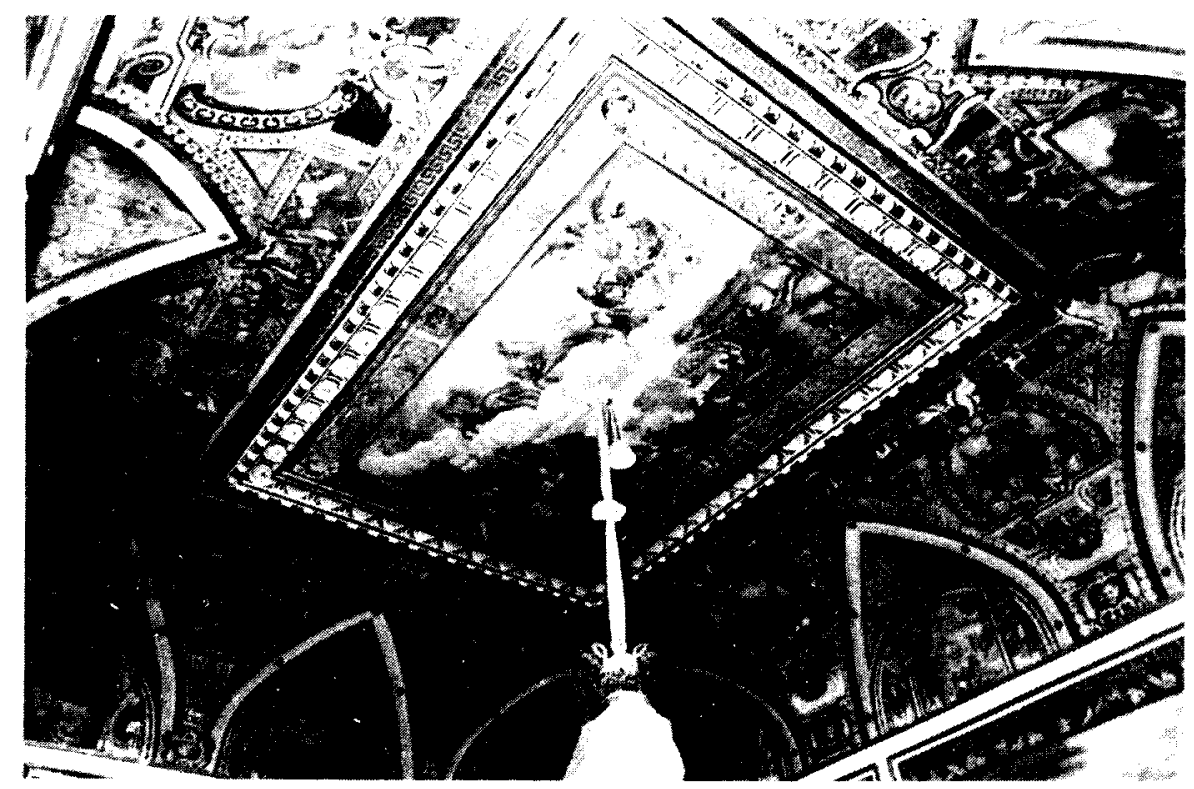

Fig. 4. Luis de Carvajal. Caceria con la Aurora. Cámara de la Reina de Hungria, según el plano de 1626. Atribuida a Vicente Carducho por Vicente Poleró.

La superficie del techo está ocupada por una escena de caza, en la parte inferior, y el Carro de la Aurora rompiendo el dia, en la superior. Aparece la joven diosa alada de pie en su carro irado por cuatro caballos blancos, arrojando flores. Junto a ella, una figura alada con un reloj de arena que representa al Tiempo, y un gallo, compañero fiel de la Aurora, que anuncia la llegada del día. El carro avanza veloz, rompiendo la noche, hácia el circulo del Zcdiaco que asoma por la parte superior derecha, y del que vemos el signo de escorpión - signo que corresponde al mes de octubre, mes de la caza-. La parte inferior de la composición presenta a un grupo de jinetes contemplando una cacería de javalies y ciervos que transcurre en segundo plano, esquema éste típico de los cuadros de batalla inspirados en estampas del Tempestad. 


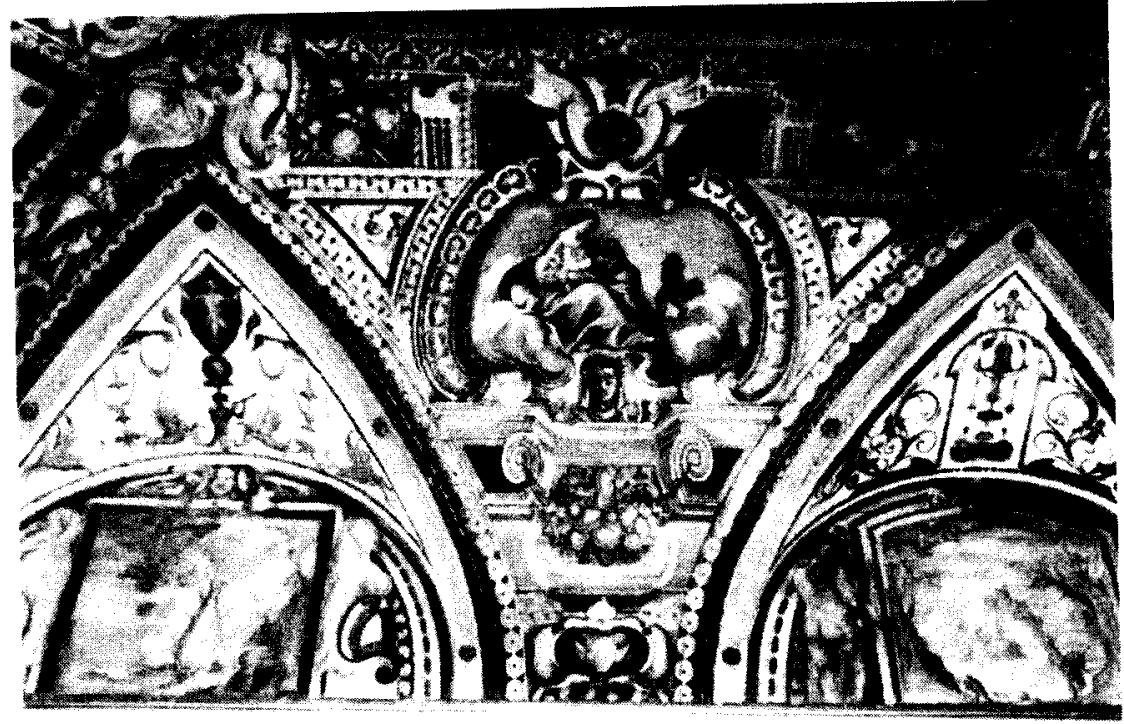

Fig. 4.1. Luis de Carvajal. La Caridad.

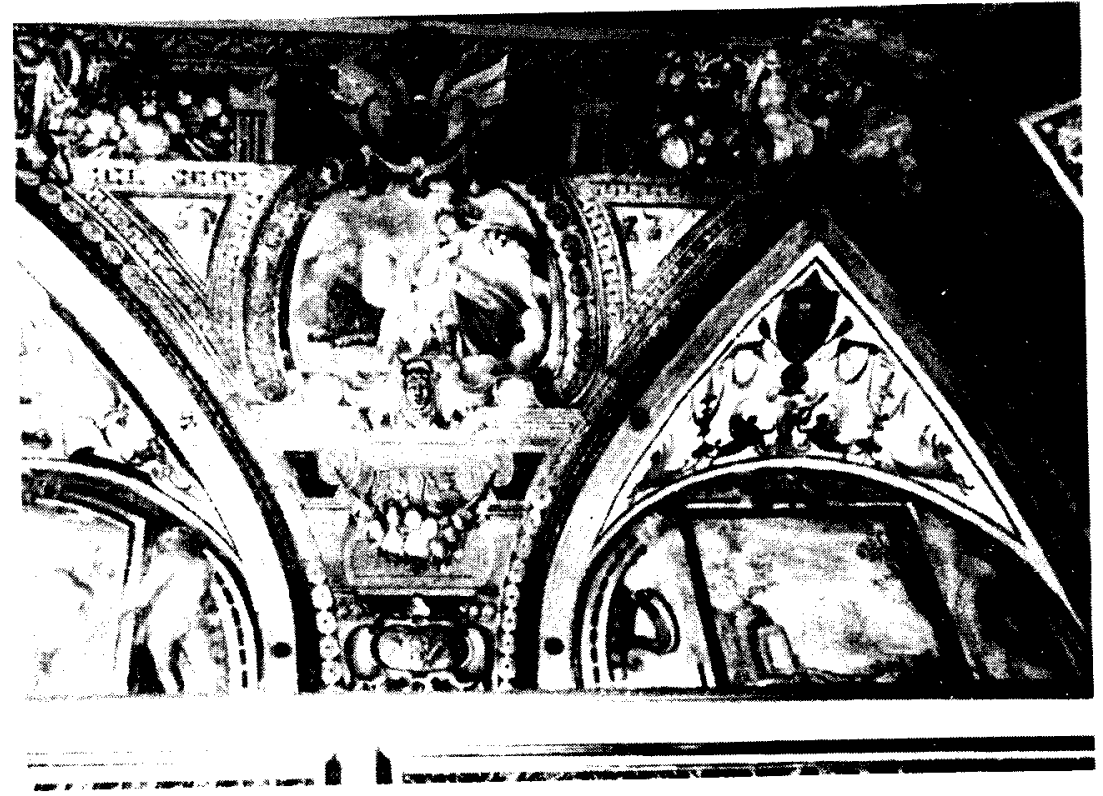

Fig. 4.2. Luis de Carvajal. La Fortaleza. 
Rodeando el techo, en la escocia, y con un riquísimo molduraje, aparecen ocho figuras femeninas que representan las virtudes. Empezamos con la Caridad, rodeada de niños que protege con su manto, acompañada por la Fortaleza, una mujer con casco militar y sosteniendo una columna; en el siguiente paño encontramos a la Templanza con sus dos recipientes, en el momento de echar agua de uno a otro, y a una mujer inclinada con un arco y una tablilla que podrian simbolizar la Esperanza (Esta representación tan poco usual de la Esperanza está tomado del Emblema XLVI de Alciato); seguimos con la Monarquia, una matrona con corona y cetro que apoya su mano derecha sobre un orbe también coronado, tras ella un león y un ciervo, y la Justicia que mira atentamente a su balanza al tiempo que nos muestra su espada; terminamos con la Pureza, dama sobriamente vestida con un tallo con lirios, y la última matrona que sujeta un ancora con su mano derecha y con la mirada puesta en los alto. Esta última matrona podría simbolizar la Fe, aunque lleve los atributos típicos de la Esperanza, pero de esta manera tendriamos todas las Virtudes - las tres Teologales y las cuatro Cardinales--

Nos queda por último los lunetos también decorados con ricos motivos a candelieri y cobijando sencillos paisajes, algunos de ellos con temas de caza.

Estamos ante una de las obras más ricas con una gran variedad de motivos decorativos, pues junto a los grutescos encontramos un abundante repertorio de molduras y enmarcamientos arquitectónicos, guirnaldas de frutos con pájaros y mascarones obteniendo como resultado un obra llena de exuberancia y opulencia.

V. FRANCISCO LOPEZ. TOMA DE GRANADA. RESTOS DE LA DECORACIÓN DEL SALÓN DE RETRATOS, TAMBIÉN LLAMADO SALÓN DE VESTIR DEL REY. INICIADO POR PANTOJA DE LA CRUZ Y SU HIJO EN 1608

Al igual que ocurrió con la Galería de la Fieina, los sucesivos uso de este Palacio han hecho que estas amplias estancias se tabicaran al desaparecer su utilidad en el siglo xvIII. De lo que fue la antigua Galería de Retratos sólo ha llegado hasta nosotros un lateral. Este fragmento está centrado en la escena de la "Toma de Granada", en el momento que el rey Boabdil, con la rodilla incada en el suelo, entrega las llaves de la ciudad a los Reyes Católicos, que aparecen montados a caballo en el lado opuesto de la composición. Al fondo una ciudad amurallada. Completan este lado dos escenas guerreras y dos representaciones fluviales. Termina 


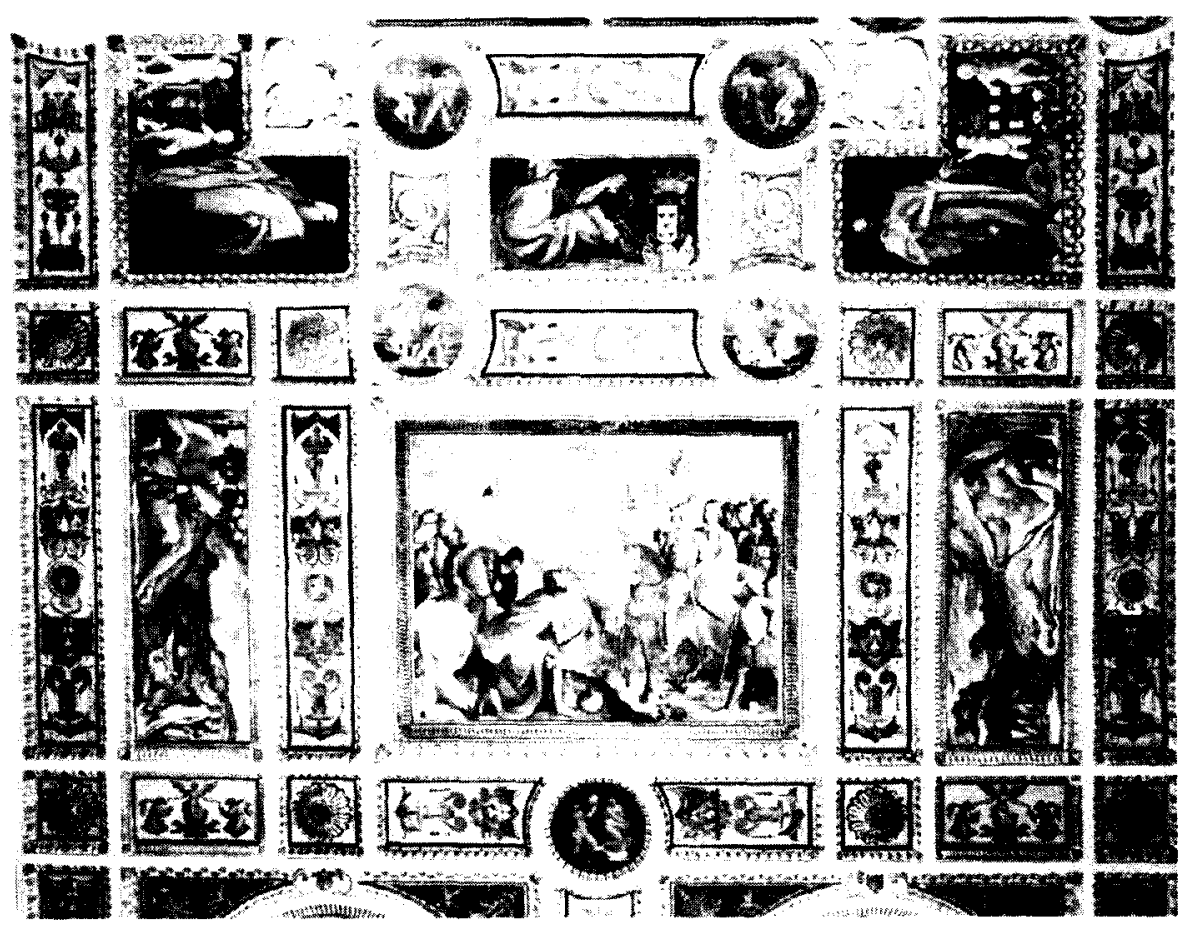

Fig. 5. Francisco López. Toma de Granada. Restos de la decoración en el Salón de Retratos, también llamado Salon de Vestir del Rey. Iniciado por Pantoja de la Cruz y su hijo en 1608, y terminado por Francisco López.

este fragmento con el arranque del siguiente tramo del techo con las escenas que rodeaban la escena principal. Se trata de tres figuras masculinas acompañadas de escudos coronados.

Parece que en un principio el techo iba a ser una exaltación a la gloria del Emperador Carlos $V$ personificado en el las aventuras de Aquiles, pero al final se prefirió esta temática, mucho más moderna, que venía a exaltar los origines y la continuidad de la monarquía hispánica de los Trastamara a los Hansburgo. Parece que el tema central fue la Entrada de Juana de Castilla y Felipe de Austria, como Reyes de España y Archiduques de Austria. Esta iconografía se completaba con las serie de retratos que decoraban las paredes, constituyendo un claro precedente de la decoración que luego se planearía para el Salón de Reinos del Buen Retiro. Pero no hay que olvidar que otro hecho de armas ocurrido durante el reinado de los Monarcas Cat́licos sirvió de tema central para la decoración de otra galería, me refiero a la Sala de Batallas del Monasterio de San Lorenzo, que con la "Toma de la Higueruela" y las escenas de la "Campaña de 
Francia» presentaban al rey Felipe $1 /$ como continuador de esta misma tradición hispánica.

\section{BIBLIOGRAFIA}

Alciato, A.: Emblemas. Madrid, 1985

Angulo, D. Pérez Sánchez, A.E.: Pintura madrileña. Primer tercio del siglo xvII. Madrid, 1969

ARgote de MOLINA, G.: Discurso sobre el Libro de Monteria que mandó escrevir el muy alto y muy poderoso Rey Don Alfonso de Castilla, y de León. Publicado por Simón Diaz en Fuentes para la Historia de Madrid y su provincia. Madrid, 1964, pág.: 118.

CARDuCho, $V$.: Diálogos de la Pintura. Madrid, 1979

KUSCHE, M.: "La antigua galeria de retratos del Pardo: su reconstrucción arquitectónica y el orden de colocación de los cuadrod" en Archivo español de Arte, 1991, número: 253.

Lopez Torfijos, R.: La Mitología en la pintura española del Siglo de Oro. Madrid, 1985. "Las pinturas de Becerra en el Palacio de El Pardo y la iconografia de Perseo y Pegaso" en Cinco siglos de Arte en Madrid $(x v-x x)$. Ill Jornadas de Arte. C.S.I.C. Madrid, 1991.

Marias, F.: "El Palacio Real de El Pardo: de Carlos $v$ a Felipe ill", en Reales Sitios, Numero extraordinario, 1989. Pág.: 137146.

Martinez Martinez, A.: "Un fresco de El Pardo atribuido a V. Carducho, documentado como de Luis de Carvajal" en Archivo Español de Arte, 1991, número: 254.

NEwCome, M: "Genoese drawings for the Queen s Gallery in El Pardo, Madrid", en Antichita Viva, núm: : 4, 1990, págs: :22-30.

PACHECHO. F.: Arte de la Pintura. Madrid, 1989.

Tovar Marifin, V.: "El Madrid de los Austrias. Siglos XVI-XVII", en Madrid Pintado, catálogo de la exposición. Madrid, 1992. 
